\title{
CONCENTRAÇÃO IÔNICA PLASMÁTICA E BILIAR DO \\ "CURIMBATÁ" PROCHILODUS SCROFA STEINDACHNER \\ (OSTEICHTHYES, CHARACIFORMES) EM RELAÇÃO AOS \\ ESTÁDIOS DE REPOUSO E MADURO DO CICLO REPRODUTIVO
}

\author{
Renata Guimarães Moreira ${ }^{1}$ \\ Olga Martins Mimura ${ }^{1}$ \\ Rossana L.V. Andrade Lima ${ }^{1}$ \\ Geraldo Bernardino ${ }^{2}$
}

\begin{abstract}
Plasmatic and biliar IONIC CONCENTRATION OF the fREShwater TELEOST Fish PROCHILODUS SCROFA STEINDACINER (OSTEICHTHYES, CharaCIFORMES), IN RELATION OF MATURATION CYCLE. Body fluid ionic content of fishes varies with ambient. Variations in the plasmatic ionic concentration have also been related with sex or maturation cycle, once that reproduction modifies metabolic processes. In fishes, the gallbladder is an important osmoregulatory organ. So, the present work has been focused on the relation of plasmatic and biliar electrolytes with sex and maturation cycle, of the teleost fish Prochilodus scrofa at the resting and mature stages of gonadal cycle. The animals ( 28 males and 30 females) were collected at Cachoeira de Emas (Pirassununga, São Paulo) and they were fasted for three days before the experiments. Deteminations of $\mathrm{Na}^{+}, \mathrm{K}^{+}, \mathrm{Mg}^{++}$, and $\mathrm{Ca}^{++}$were made by spectophotometry and $\mathrm{Cl}^{-}$by microtitulation. Comparisons of ionic content between sex and maturation cycle were assessed using analysis of variance and Student-Newman-Keuls test. In this work it was seen that in males and females at resting and mature stages, there are no difference at ionic plasmatic content. $\mathrm{K}^{+}$contents were higher in the bile of mature males than in resting ones. $\mathrm{Mg}^{++}$biliar contents were higher in resting males than in resting and mature males. $\mathrm{Na}^{+}, \mathrm{Ca}^{++} \mathrm{e} \mathrm{Cl}^{-}$contents have no difference. $\mathrm{Na}^{+}$, $\mathrm{K}^{+}, \mathrm{Ca}^{++}$and $\mathrm{Mg}^{++}$contents were higher in the bile than in the plasma. $\mathrm{Cl}^{-}$content was higher in plasma than in bile.Variations related with proteic synthesis, and another metabolic processes during cycle, may be the reason of variations in the biliar ionic content.

KEY WORDS. Osteichthyes, Characiformes, Prochilodus scrofa, bile, plasma, ionic content
\end{abstract}

Os teleósteos dulciaquícolas têm concentração osmótica plasmática muito superior à da água do meio; são, portanto, hiperosmóticos em relação ao meio em que vivem e, desta forma, tendem a ganhar água por osmose e perder íons por

1) Departamento de Fisiologia, Instituto de Biociências, Universidade de São Paulo. Caixa Postal 11461, 05422-970 São Paulo, Săo Paulo, Brasil.

2) Centro de Pesquisa e Treinamento em Aqüicultura, Cepta/lbama. Caixa Postal 64, 13630-000 Pirassununga, São Paulo, Brasil.

Revta bras. Zool. 15 (1): 211 - 217, 1998 
difusão, através das brânquias. Para controlar estes problemas, estes animais reabsorvem íons monovalentes pelos rins, bexiga urinária e células de cloreto nas brânquias e membrana opercular (KIRSCH et al. 1984). Na bexiga urinária ocorre absorção de sódio e excreção de potássio, sendo o transporte de cloreto acoplado ao de sódio (Evans 1979).

Teleósteos marinhos têm o sangue hiposmótico em relação ao meio, perdendo água por osmose através das brânquias e urina, e ganhando íons por difusão através das brânquias, esôfago e intestinos. Em algumas espécies ainda, o excesso de sais é eliminado pela pele, como em Blennius pholis Linnaeus (NonNOTE et al. 1979).

Variações na concentração iônica plasmática também têm sido relacionadas ao sexo e/ou estádio de maturação do animal.

Cátions divalentes vem merecendo cada vez mais a atenção, já que regulam grande número de eventos celulares. O papel destes cátions na maturação do oócito e ativação do ovo na fertilização tem sido estudado intensivamente nos últimos anos.

Existem outros fatores associados a íons e reprodução, como, por exemplo, a produção de sêmen. Estudos feitos por BAYNES \& SCOTT (1985) correlacionando níveis plasmáticos de $17 \alpha, 20 \beta$ hidroxiprogesterona, níveis plasmáticos e seminais de sódio e potássio com produção de sêmen em truta, mostraram que a concentração de $17 \alpha, 20 \beta$ hidroxiprogesterona permaneceu elevada durante o período de produção de sêmen. Postulou-se que esse esteróide estaria associado com o controle da composição iônica do fluído seminal.

Em pacu foi observada uma forte influência do ciclo sexual nos níveis de sódio, cálcio e magnésio, com elevação desses parâmetros em fêmeas durante a maturação avançada, e diferenças também entre os sexos, sendo os níveis de potássio mais elevados em machos.

Em peixes, os primeiros estudos da bile foram feitos por BABKIN (1929) e MACKAY (1929), que observaram parâmetros enzimáticos e pH em algumas espécies. Diamond (1962a) e HunN $(1972,1976)$ descreveram a composição da bile vesicular e do plasma de várias espécies de teleósteos (Abramis blicca, Rutilus rutilus Linnaeus, Lepisosteus plastotomus, Amia calva Linnaeus, Salmo trutta Linnaeus, Salvelinus fontinalis Mitchill, Cyprinus carpio Linnaeus e Ictalurus natalis), assim como seu pH. MiMURA \& BALDISSEROTTO (1988) demonstraram a composição iônica plasmática de Prochilodus affinis Reinhardt, 1874 e Prochilodus marggravii Walbaum, 1792.

HIRANO \& BERN (1972) demonstraram não haver diferença na taxa de absorção de água e íons na vesícula isolada de peixes marinhos ou dulciaquícolas.

BALDISSEROTTO et al. (1990) determinaram os teores iônicos plasmáticos e biliares em três espécies do gênero Prochilodus, Prochilodus affinis Reinhardt, 1874; Prochilodus marggravii Walbaum, 1792 e Prochilodus scrofa Steindachner, 1881 e uma do gênero Synbranchus (Synbranchus marmoratus Bloch, 1795), verificando, não haver variações nos teores de sódio e potássio nestes animais, coletados em locais diferentes, sugerindo que o hábito alimentar não modifica o conteúdo iônico biliar. 
O objetivo do presente trabalho foi verificar possíveis diferenças nas concentrações dos íons sódio, potássio, cálcio, magnésio e cloreto, no plasma e na bile, de machos e fêmeas do curimbatá, coletado em ambiente natural, nos estádios maduro e repouso, do ciclo gonadal.

\section{MATERIAL E MÉTODOS}

Os animais utilizados foram peixes teleóstes da espécie Prochilodus scrofa Steindachner, 1881 (Osteichthyes, Characiformes, Prochilodontidae), cuja denominação vulgar no Brasil, varia, sendo chamados de curimbatá, corimbatá, corumbatá, curimba e papa-terra (GoDOY 1975).

As capturas foram feitas com tarrafa, no rio Mogi-Guaçu, na região de Pirassununga (Cachoeira de Emas) (21 $\left.1^{\circ} 58^{\prime} \mathrm{S}-47^{\circ} 26^{\prime} \mathrm{W}\right)$, São Paulo, por funcionários do CEPTA/IBAMA (Centro de Pesquisa e Treinamento em Aquicultura do Instituto Brasileiro do Meio Ambiente e Recursos Naturais Renováveis).

Depois de coletados, os animais foram mantidos em tanques de fibra de vidro de 3.0001, com fluxo de água contínuo, no CEPTA/IBAMA, por 3 dias, sem alimentação.

Todos os animais (58 no total, sendo 28 machos e 30 fêmeas, nos estádios de Repouso e Maduro) tiveram seus parâmetros ponderais (peso total e gonadal) e morfométricos (comprimento total) determinados.

O sangue coletado (cerca de $5 \mathrm{ml}$ ) com seringas descartáveis, heparinizadas (Liquemine-Roche, 5000 UI, em uma diluição de 1:1), por punção da vasculatura caudal, foi centrifugado por cinco minutos a $3000 \mathrm{rpm}$ e o plasma congelado a $-18^{\circ} \mathrm{C}$, para posterior análise iônica. Não foi utilizado nenhum tipo de anestésico antes da coleta do sangue, pois estas substâncias frequentemente alteram os teores iônicos plasmáticos.

Para a retirada dos órgãos, os animais foram sacrificados seccionando-se a medula espinhal anterior ao nível do opérculo. A cavidade abdominal foi aberta, retirando-se a vesícula biliar e coletando-se a bile em tubos de "eppendorf" que foi armazenada e congelada também a $-18^{\circ} \mathrm{C}$, para posterior análise iônica.

Como o "curimbatá" não apresenta dimorfismo sexual externo, determinaram-se macroscopicamente, o sexo e o estádio de maturação pela observação das gônadas in situ. Estas, posteriormente foram retiradas e pesadas, para o cálculo do I.G.S. (Índice-Gonadossomático).

A determinação das concentrações iônicas foi feita em espectofotômetro de chama (Zeiss PM Q1-II) por emissão (sódio e potássio) e absorção atômica (cálcio e magnésio). O cloreto foi determinado por microtitulometria, pelo método de SCHALES \& SCHALES (1941), utilizando-se microtitulador Beckmam mod. 153.

Foram analisados os dados relacionados às concentrações iônicas levando-se em consideração, o sexo e o estádio de maturação. O teste estatístico utilizado foi o de análise de variância (ANOVA) e Student-Newman-Keuls (SNK) através do programa computacional Primer of Biostathystic, Copyright 1988 by McGraw-Hill. 


\section{RESULTADOS}

Os dados apresentados na tabela I indicam que no "curimbatá", machos e fêmeas em Repouso e Maduros não apresentam variações iônicas plasmáticas. Quanto à concentração iônica biliar, verificou-se que machos Maduros exibiram concentração de potássio mais elevada que machos em Repouso. Já para o magnésio biliar, os resultados mostraram que machos em Repouso apresentaram concentrações mais elevadas que fêmeas em Repouso e Maduras. Com relação aos íons sódio, cálcio e cloreto, não foram observadas alterações significativas.

Os íons analisados mostram concentrações mais elevadas na bile que no plasma, sendo a única exceção o cloreto, que apresentou níveis plasmáticos mais elevados.

Tabela I. Concentração plasmática e biliar dos íons sódio, potássio, cálcio, magnésio e cloreto ( $\mathrm{mEq} / \mathrm{l})$ em machos e fêmeas de Prochilodus scrofa Maduros e em Repouso.

\begin{tabular}{|c|c|c|c|c|c|c|c|c|}
\hline \multirow{3}{*}{$\underset{(m E q / l)}{\text { lon }}$} & \multicolumn{4}{|c|}{ Plasma } & \multicolumn{4}{|c|}{ Bile } \\
\hline & \multicolumn{2}{|c|}{ Macho } & \multicolumn{2}{|c|}{ Fêmea } & \multicolumn{2}{|c|}{ Macho } & \multicolumn{2}{|c|}{ Fêmea } \\
\hline & $\begin{array}{l}\text { Maduro } \\
(n=15)\end{array}$ & $\begin{array}{l}\text { Repouso } \\
(n=13)\end{array}$ & $\begin{array}{l}\text { Maduro } \\
(n=5)\end{array}$ & $\begin{array}{l}\text { Repouso } \\
(n=20)\end{array}$ & $\begin{array}{l}\text { Maduro } \\
(n=15)\end{array}$ & $\begin{array}{l}\text { Repouso } \\
(n=13)\end{array}$ & $\begin{array}{c}\text { Maduro } \\
(n=5)\end{array}$ & $\begin{array}{l}\text { Repouso } \\
(n=20)\end{array}$ \\
\hline Sódio & $154,7 \pm 39,2$ & $129,8 \pm 37,3$ & $146,8 \pm 48,5$ & $132,1 \pm 30,7$ & $191,0 \pm 47,5$ & $230,9 \pm 83,9$ & $214,0 \pm 80,2$ & $230,5 \pm 62,4$ \\
\hline Potássio & $2,6 \pm 1,3$ & $2,5 \pm 0,5$ & $3,1 \pm 1,0$ & $3,0 \pm 0,8$ & $8,0 \pm 2,7^{\star}$ & $5,6 \pm 1,7$ & $5,6 \pm 2,1$ & $7,2 \pm 2,3$ \\
\hline Magnésio & $1,7 \pm 0,5$ & $1,6 \pm 0,3$ & $1,8 \pm 0,4$ & $1,7 \pm 0,4$ & $2,6 \pm 1,1$ & $3,5 \pm 1,3^{* *}$ & $1,8 \pm 0,6$ & $2,3 \pm 1,4$ \\
\hline Cálcio & $3,8 \pm 0,9$ & $4,1 \pm 0,7$ & $3,9 \pm 0,8$ & $4,0 \pm 1,0$ & $13,3 \pm 3,0$ & $13,7 \pm 2,9$ & $10,5 \pm 1,1$ & $12,7 \pm 0,8$ \\
\hline Cloreto & $83,7 \pm 15,6$ & $94,9 \pm 15,3$ & $82,4 \pm 19,6$ & $85,9 \pm 15,1$ & $13,7 \pm 3,8$ & $12,3 \pm 6,1$ & $13,3 \pm 4,6$ & $12,8 \pm 5,9$ \\
\hline
\end{tabular}

$\left(^{*}\right)$ concentração significativamente maior que machos em repouso $(p<0.05) ;\left(^{* \star}\right)$ concentração significativamente maior que fêmeas (repouso e maduras) $(p<0.05)$; média \pm desvio padrão; (n) número de indivíduos.

\section{DISCUSSÃO E CONCLUSÕES}

Os teores iônicos plasmáticos e biliares em $P$. scrofa são semelhantes aos descritos para outras espécies de teleósteos.

Na literatura encontram-se diferenças em relação à concentração de cálcio plasmático, sendo esta maior em fêmeas que em machos (VINOGRADOV 1953). Outros autores, ainda, têm verificado hipercalcemia plasmática em peixes durante a vitelogênese (FONTAINE et. al. 1969; JOHNSON \& CASILLAS 1991) e ainda níveis mais elevados de cálcio plasmático em fêmeas de Rhamdia hilarii, no período de reprodução. Estas elevações têm sido associadas ao aumento do estradiol na fase de maturação ovariana (WOODHEAD 1968; NG \& IDLER 1983).

As fêmeas de $P$. scrofa apresentaram concentração plasmática de cálcio ligeiramente maior que os machos, mas estes valores não diferiram estatisticamente.

Foi observada elevação na concentração dos íons sódio, cálcio, potássio e magnésio plasmáticos em fêmeas de "pacu" (Piaractus mesopotamicus Holmberg, 1887), durante a maturação avançada, sendo os níveis de potássio mais elevados em machos. E ainda, nesta mesma espécie, foram observados níveis mais elevados de glicose, proteínas e eletrólitos plasmáticos, o que atribuiram, possivelmente, a uma 
redução no consumo de energia e ao bloqueio reprodutivo que ocorre em peixes que não realizaram a migração.

Poucas são as informações disponíveis sobre a concentração iônica da bile vesicular, sendo pioneiros, em peixes, os trabalhos de DiAMOND (1962a,b) em Rutilus rutilus e Abramis blicca e de HunN (1972) em Amia calva, Salmo trutta, Salvelinus fontinalis, Cyprinus carpio e Ictalurus natalis.

Sabe-se também que o epitélio da vesícula biliar transporta ativamente $\mathrm{NaCl}$ no sentido mucosa-serosa, sem dar origem a nenhuma diferença de potencial (DIAMOND 1962a,b; HiRANO \& BERN 1972).

O que ocorre não só para peixes, mas para vários mamíferos, é que a concentração dos cátions é sempre mais elevada na bile que no plasma; já para os ânions, ocorre o inverso, sendo isto observado para o cloreto e também para o bicarbonato (WHEELER 1968). O mesmo autor explica este fato pela formação de componentes conjugados de sais biliares em mamíferos, que aparecem na bile como ânions monovalentes em quantidades consideráveis.

As concentrações iônicas biliares mais elevadas que as plasmáticas (com exceção ao cloreto) também foram observadas para outras espécies da família Prochilodontidae (Prochilodus marggravii e Prochilodus affinis); em Synbranchus marmoratus (BALDiSSEROTTO et al. 1990) e em Abramis blicca e Rutilus rutilus (DIAMOND 1962a).

Comparando-se agora os valores do presente trabalho, com aqueles obtidos por BALDISSEROTTO et al. (1990) para a bile da mesma espécie, verifica-se que estes são muito próximos.

Em experimentos realizados no mesmo laboratório, com administração da urotensina II (UII), hormônio produzido pelo Sistema Neurossecretor Caudal foi observado que em $P$. scrofa o teor de $\mathrm{Mg}^{++}$biliar em machos do grupo controle é mais elevado que as fêmeas do mesmo grupo e, também, aquelas injetadas com UII na concentração de $10^{-7} \mathrm{M}$. Neste mesmo trabalho, foi verificado que a UII também na concentração de $10^{-7} \mathrm{M}$ causa elevação dos teores de $\mathrm{K}^{+}$biliar em machos.

Ainda utilizando a UII, BALDISSEROTTO et. al. (1996) observaram que este hormônio aumenta a absorção de água e inibe a secreção de $\mathrm{Ca}^{++}$na vesícula biliar de Hoplias malabaricus Bloch, 1794.

DiAMOND (1962a) e HIRANO \& BERN (1972) utilizando doses elevadas de ocitocina, observaram inibição do influxo de água na vesícula biliar isolada de Rutilus rutilus Linnaeus e de Anguilla japonica. O mesmo aspecto foi observado em Platichthys stelatus Pallas sob ação da arginina-vasotocina (AVT) (HIRANO \& BERN 1972). Pode-se inferir que esta inibição do influxo de água acompanha a inibição simultânea do influxo de $\mathrm{Na}^{+} \mathrm{e} \mathrm{K}^{+}$.

Pelos dados acima mencionados sugere-se que à semelhança da UII, outros hormônios relacionados ou não à reprodução possam estar atuando no epitélio transportador da vesícula biliar.

AGRADECIMENTOS. Ao CEPTA/IBAMA, pelo apoio e uso das instalações; à CAPES (Coordenadoria de Aperfeiçoamento de Pessoal de Ensino Superior), pela bolsa concedida durante o período desta pesquisa.

Revta bras. Zool. 15 (1): 211 - 217, 1998 


\section{REFERÊNCIAS BIBLIOGRÁFICAS}

BABKIN, B.P. 1929. Studies on the pancreatic secretion in snakes. Biol. Bull., Woods Hole, 57: 272-91.

Baldisserotto, B.; O.M. Mimura \& L.C. Salomão. 1990. Gallbladder and plasma ionic content of some freshwater teleosts. Bol. Fisiol. Anim. USP, São Paulo, 14: 7-11.

Baldisserotto, B.; R.J. Rakoski; C.L.S. Fernandes \& O.M. Mimura. 1996. Effect of Urotensin II on water and ion fluxes in the intestine, gallbladder and urinary bladder of the freshwater teleost, Hoplias malabaricus. Ciência e Natura, Santa Maria, 18: 71-82.

BAYNES, S.M. \& A.P. SCOTT. 1985. Seasonal variation in parameters of milt production and in plasma concentrations of sex steroids of male rainbow trout Salmo gairdneri. Gen. Comp. Endocrinol., Salem, 57: 150-60.

Diamond, J.M. 1962a. The reabsortive function of the gallbladder. Jour. Physiol., Cambridge, 161: 442-473.

1962b. The mechanism of solute transport by the gall-bladder. Jour. Physiol., Cambridge, 161: 474-502.

Evans, D.H. 1979. Fish, p.305-390. In: G.M.O. MaloIY (Ed.). Comparative Physiology of Osmoregulation in animals. London, Academic Press, Vol. 1, $677 \mathrm{p}$.

Fontaine, M.; M. Chartier-Baraduc; J. Durtle; E. Lopes \& M. Poncet. 1969. Sur les variations de la calcemie observees chez Salmo salar L. a divers etapes de son cicle vital. Leur determination endocrinien et leur intervention eventuelle sur le comportement. C.R.Acad.Sci., Paris, D268: 1958-1961.

Godoy, M.P. 1975. Peixes do Brasil-Subordem Characoidei-Bacia do rio MogiGuassu. Piracicaba, Franciscana, 181p.

Hirano, T. \& BERN, H.A. 1972. The teleost gallbladder as an osmoregulatory organ. Endocrinol. Jpn., Tokyo, 19 (1): 41-46.

HunN, J.B. 1972. Concentrations of some inorganic constituents in gallbladder bile from some freshwater fishes. Copeia, New York, (4): 860-61.

- 1976. Inorganic composition of gallbladder bile from freshwater fishes. Copeia, New York, (3): 602-5.

Johnson, L.L. \& E. CASILLAS. 1991. The use of plasma parameters to predict ovarian maturation stage in English sole Parophrys vetulus Girard. Jour. Exp. Mar. Biol. Ecol., Amsterdam, 151: 257-70.

Kirsch, R.; W. HUMBeRT \& J.L. RODEAU. 1984. Control of the blood osmolarity in fishes with reference to the funcional anatomy of the gut, p.68-93. In: A. PequeuX; R.R. Gilles; L. Bolis (Eds). Osmoregulation in estuarine and marine animals. Berlin, Springer, 232p.

MACKAY, M.E. 1929. Note on bile in different fishes. Biol. Bull., Woods Hole, 56: 24-7.

Mimura, O.M. \& B. BALdisserotTo. 1988. Plasma ionic and osmotic concentration of two freshwater teleosts, Prochilodus affinis and Prochilodus marggravii 
in different gonadal stages. Bol. Fisiol. Anim. USP, São Paulo, 12: 21-30.

NG, T.B. \& D.R. IDLER. 1983. Yolk formation and differentiation in teleost fishes, p.303-404. In: W.S. Hoar; D.J. Randall; E.M. Donaldson. (Eds). Fish Physiology. New York, Academic Press, IXA, 483 p.

NonNote, G.; L. NonNote \& R. KIrSCH. 1979. Chloride cells and chloride exchange in the skin of a seawater teleost, the shanny (Blennius pholis L.). Cell. Tissue Res., Heildelberger, 199: 387-96.

Schales, O. \& S.S. Schales. 1941. A simple and accurate method for the determination of chloride in biological fluids. Jour. Biol. Chem., Baltimore, 140: 879-84.

VINOGRADOV, A.P. 1953. The elementary chemical composition of marine organisms. Mem. Sears. Fdn. Mar. Res. (2): 647.

WHEELER, H.O. 1968. Water and electrolytes in bile, p.2409-2431. In: C.F. CoDE; W. HeIDEl (Eds). Handbook of Physiology. Washington, Amer. Phys. Soc., Vol. 5, Sect. 6, XXIV+2896p.

WOODHEAD, P.M.J. 1968. Seasonal changes in the calcium content of the blood of artic cod. Jour. Mar. Biol. Assoc. Cambridge, U.K., 48: 81-91.

Recebido em 04.VII.1997; aceito em 17.IV.1998. 